The Preliminary Evaluation of 4-METHYLCYCLOHEXYLMETHANOL IN AN IN VITRO HUMAN AIRWAY MODEL

NTP RR 7

DECEMBER 2018 


\title{
NTP Research Report on the Preliminary Evaluation of 4-Methylcyclohexylmethanol in an In Vitro Human Airway Model
}

\author{
Research Report 7 \\ National Toxicology Program
}

December 2018

National Toxicology Program

Public Health Service

U.S. Department of Health and Human Services

ISSN: 2473-4756 


\section{Table of Contents}

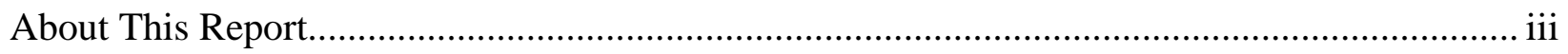

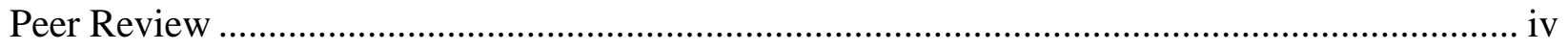

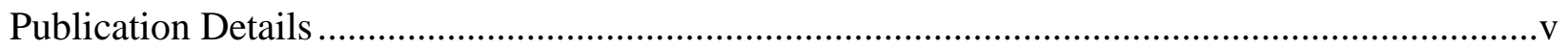

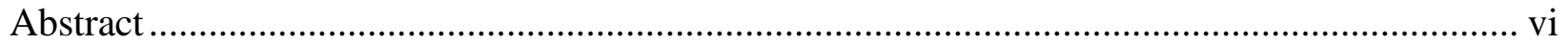

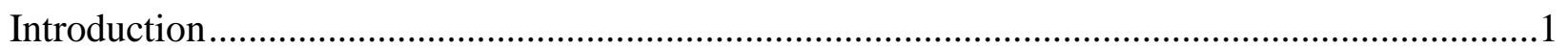

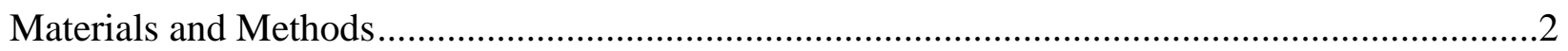

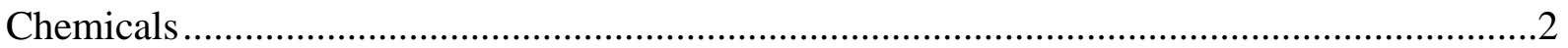

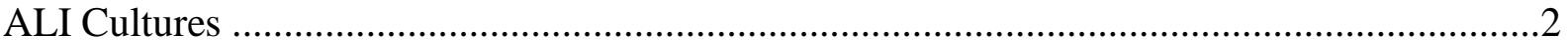

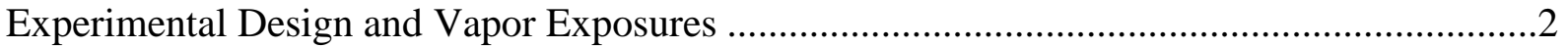

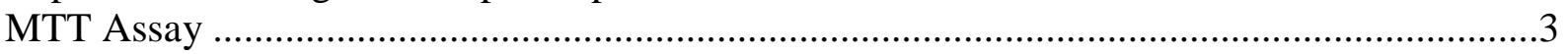

IL-1 Receptor Activation Assay.................................................................................. 3

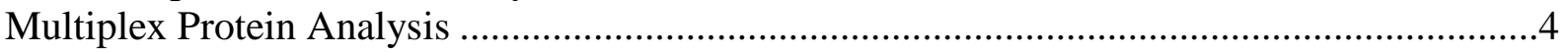

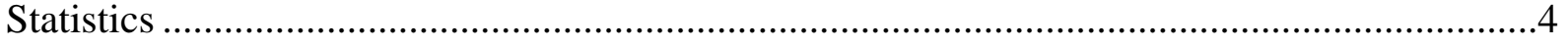

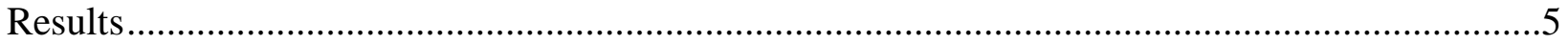

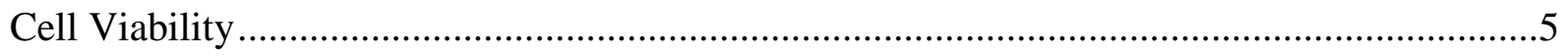

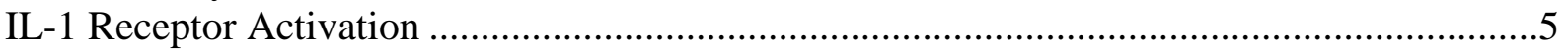

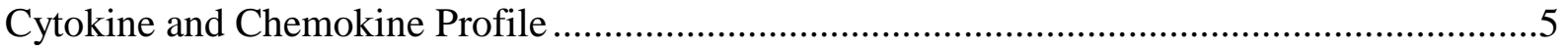

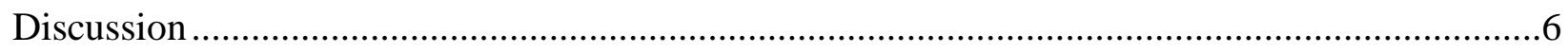

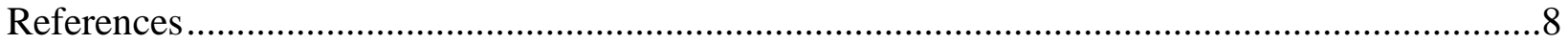

\section{Figures}

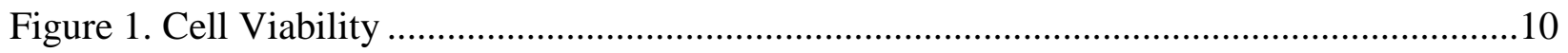

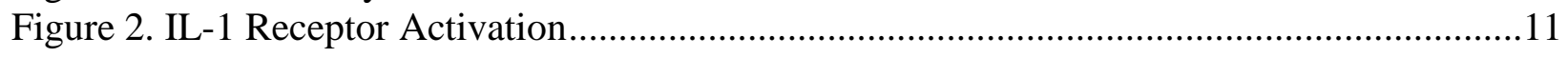

Figure 3. Cytokine and Chemokine Production .....................................................................13 


\title{
About This Report
}

\author{
Authors \\ William M. Gwinn ${ }^{1}$, Ronald W. Bousquet ${ }^{2}$, Caroline E. Perry ${ }^{1}$, Nancy C. Urbano ${ }^{1}$, Scott S. \\ Auerbach ${ }^{1}$ \\ ${ }^{1}$ Division of the National Toxicology Program, National Institute of Environmental Health \\ Sciences, Research Triangle Park, North Carolina, USA \\ ${ }^{2}$ Alion Science and Technology Corporation, Research Triangle Park, North Carolina, USA \\ Division of the National Toxicology Program, National Institute of Environmental Health \\ Sciences, Research Triangle Park, North Carolina, USA \\ Scott S. Auerbach, Ph.D. \\ William M. Gwinn, Ph.D. \\ Caroline E. Perry, B.S. \\ Nancy C. Urbano, B.S. \\ Alion Science and Technology Corporation, Research Triangle Park, North Carolina, USA \\ Ronald W. Bousquet, M.S.
}

\section{Contributors}

Division of the National Toxicology Program, National Institute of Environmental Health Sciences, Research Triangle Park, North Carolina, USA

Oversight of peer review

Mary S. Wolfe, Ph.D.

ICF, Durham, North Carolina, USA

Contract oversight

David F. Burch, M.E.M.

Technical editing and document production

Tara Hamilton, M.S.

Katherine R. Helmick, M.P.H.

Peer review support

Susan E. Blaine, B.A.

Natalie K. Blanton, M.P.H. 


\section{Peer Review}

The draft research report, Preliminary Evaluation of 4-Methylcyclohexylmethanol in an In Vitro Human Airway Model, was evaluated by the reviewers listed below. These reviewers served as independent scientists, not as representatives of any institution, company, or governmental agency. In this capacity, reviewers determined if the design and conditions of these NTP studies were appropriate and ensured that this NTP Research Report presented the experimental results and conclusions fully and clearly.

\section{Peer Reviewers}

\section{Frank A. Barile, Ph.D.}

Professor

College of Pharmacy and Health Sciences

St. John's University

Queens, New York, USA

\section{Ilona Jaspers, Ph.D.}

Professor

Department of Environmental Sciences and Engineering

Department of Pediatrics, Microbiology, and Immunology

University of North Carolina at Chapel Hill

Chapel Hill, North Carolina, USA 


\section{Publication Details}

Publisher: National Toxicology Program

Publishing Location: Research Triangle Park, NC

ISSN: 2473-4756

DOI: https://doi.org/10.22427/NTP-RR-7

Report Series: NTP Research Report Series

Report Series Number: 7

Official citation: Gwinn WM, Bousquet RW, Perry CE, Urbano NU, Auerbach SS. 2018. NTP Research Report on the Preliminary Evaluation of 4-Methylcyclohexylmethanol in an In Vitro Human Airway Model. NTP RR 7. Research Triangle Park, NC: National Toxicology Program (7): 1-19.

\section{Acknowledgments}

This research was supported by the National Institute of Environmental Health Sciences/Division of the National Toxicology Program. 


\section{Abstract}

In the aftermath of the large spill of crude 4-methylcyclohexylmethanol (MCHM) into the Elk River in 2014, there were reports of a strong licorice-smelling odor and reports of respiratory illness/cough suggestive of chemical-induced adverse airway effects. Levels of MCHM in the air were predicted to be as high as $0.39 \mathrm{ppm}$ after 10 minutes of showering, suggesting that inhalation of MCHM vapors was a potential route of chemical exposure. NTP conducted prenatal developmental toxicity and 5-day toxicogenomic oral gavage studies that showed minimal MCHM-induced adverse effects; however, no in vivo inhalation studies for MCHM have been performed to date. In this study, we utilized an organotypic human air-liquid interface (ALI) culture model (EpiAirway ${ }^{\mathrm{TM}}$ ) derived from a single donor to determine if there was any potential for MCHM-induced airway toxicity in vitro following acute exposure to MCHM vapors for 6 hours, which might warrant future inhalation toxicity testing in vivo. ALI tissues were exposed to estimated nominal vapor concentrations of 35 or $350 \mathrm{ppm}$ MCHM (pure or crude) for 6 hours using vapor cups (and calculations based on Henry's law constants derived by Sain et al.). In this model, $350 \mathrm{ppm}$ was selected as the top dose because 350-400 ppm was estimated to be the highest achievable nominal vapor concentration for exposures based on the maximum solubility (17.6 mM) of pure MCHM in water. Cell viability (using an MTT assay) and evidence of a MCHM-induced pro-inflammatory response in culture media (using interleukin (IL)-1 receptor activation and multiplex cytokine/chemokine assays) were measured at 24 hours. Acute exposure to MCHM vapors for 6 hours at these concentrations, which were $~ 90$ - to 900-fold greater than human exposure levels as predicted while showering, induced no airway cytotoxicity or proinflammatory response. In contrast, acute exposure of ALI tissues for 1.5 hours to very high vapor concentrations (estimated $>150,000 \mathrm{ppm}$ ) derived from pure or crude $7 \mathrm{M}$ MCHM as positive controls induced a potent cytotoxic and pro-inflammatory response at 24 hours. Based on these preliminary data using the EpiAirway ${ }^{\mathrm{TM}}$ ALI model derived from a single donor, acute exposure of human airway epithelial tissues to MCHM vapors for 6 hours was not toxic in vitro at concentrations relevant to human inhalation exposure $(<0.50 \mathrm{ppm})$. 


\section{Introduction}

In 2014, a large volume (10,000 gallons) of crude MCHM, used in the processing of coal, was spilled into the Elk River, which contaminated the drinking water of 300,000 West Virginians ${ }^{1}$. Strong licorice-smelling odors were reported for weeks in the air and water following the spill ${ }^{2}$ and thus potential routes of MCHM exposure included both inhalation and ingestion of contaminated water. Local residents complained of acute adverse health effects including skin and eye irritation, nausea, vomiting, as well as diarrhea, which were consistent with exposure to MCHM present in the air and drinking water, and there were 369 reported visits to the emergency room in the 2 weeks after the spill ${ }^{3 ; 4}$. In addition, there were reports of respiratory illness/cough ${ }^{4}$ suggestive of chemical-induced adverse airway effects. Inhalation of MCHM vapors while showering was also possible due to the elevated water temperature, duration of exposure and small, enclosed space ${ }^{5}$. In the study by Sain et al. ${ }^{5}$, the air concentration of MCHM in showers was predicted to be as high as $0.39 \mathrm{ppm}$ after 10 minutes. NTP conducted prenatal developmental toxicity and 5-day (oral gavage) toxicogenomic studies that showed minimal MCHM-induced adverse effects ${ }^{6}$; however, no in vivo inhalation studies for MCHM have been performed to date. Therefore, the objective of this study was to determine if there was any potential for acute MCHM-induced airway toxicity in vitro, which might warrant future inhalation toxicity testing in vivo. Airway effects (cytotoxicity and pro-inflammatory response) following acute exposure to MCHM vapors at $\sim 35$ or $350 \mathrm{ppm}$ for 6 hours were characterized in vitro using an organotypic human ALI culture model (EpiAirway ${ }^{\mathrm{TM}}$ ) derived from a single donor. In this model, $350 \mathrm{ppm}$ was selected as the top dose because 350-400 ppm was estimated to be the highest achievable nominal vapor concentration for exposures based on the maximum solubility (17.6 mM) of pure MCHM in water. We have previously used this in vitro human ALI model derived from the same donor to characterize the airway toxicity of diacetyl vapors ${ }^{7-9}$. 


\section{Materials and Methods}

\section{Chemicals}

Pure MCHM (CAS no. 34885-03-5; Lot no. KDY3F) and crude MCHM (CAS no. 34885-03-5; Lot no. TP14044373) were obtained from MRIGlobal (Kansas City, MO), and both were mixtures of the cis- and trans-isomers of MCHM. The crude MCHM used in this study consisted of $\sim 77 \%$ MCHM.

\section{ALI Cultures}

EpiAirway ${ }^{\mathrm{TM}}$ tissues, generated from primary human tracheobronchial epithelial (TBE) cells from a single, healthy (non-smoking), male donor (TBE-20), were purchased from MatTek (Ashland, MA). Cell types (and potential cell-cell interactions) present within EpiAirway ${ }^{\mathrm{TM}}$ tissues include ciliated and non-ciliated epithelial cells, goblet cells, and basal cells. These tissues are well-differentiated, functional (cilia-beating and mucus-producing), organotypic, and three-dimensional human airway epithelial tissues, which are cultured on microporous transwell (9 mm internal diameter) membranes in plastic inserts. Tissues were cultured at the ALI in $1 \mathrm{~mL}$ of AIR-100 culture medium (provided by MatTek) in 6-well plates at $37^{\circ} \mathrm{C}$ (in $5 \% \mathrm{CO}_{2}$ and $100 \%$ humidity) for the duration of experiments. The basolateral side of the tissue was submerged in the culture medium. Upon receipt from MatTek, the tissues were acclimated for a minimum of $\sim 20$ hours prior to the start of experiments.

\section{Experimental Design and Vapor Exposures}

ALI tissues were exposed to 1.55 or $15.5 \mathrm{mM}$ MCHM-derived vapors for 6 hours using vapor cups (provided by MatTek) as we have previously described for diacetyl ${ }^{7 ; 8 ; 10}$. This vapor cup method allowed for exposure of the apical surface to vapor (a physiologically relevant route of exposure for inhaled MCHM), instead of liquid chemical. The apical surface of the ALI tissues was gently rinsed twice with $400 \mu \mathrm{L}$ PBS prior to exposure. Rinsing of the apical surface removes mucus and thus in part mimics mucociliary clearance. For exposures, $50 \mu 1$ of 1.55 or $15.5 \mathrm{mM}$ pure MCHM or water vehicle only (control) was applied to the glass fiber absorbent pad in a vapor cup which was then inverted, sealed tightly (using silicone) onto the plastic transwell insert holding the tissue ${ }^{11}$, and then removed after an exposure duration of 6 hours. The tissues were then cultured for an additional 18 hours post-exposure ( 24 hours total). The aqueous MCHM concentrations of 1.55 and $15.5 \mathrm{mM}$ were estimated to produce nominal vapor concentrations of $\sim 35$ and $350 \mathrm{ppm}$, respectively, at $37^{\circ} \mathrm{C}$ (in the headspace) based on the calculation as we have previously used for diacety ${ }^{10}$ and as shown below (Equation 1) using Henry's law constant (HLC) at $40^{\circ} \mathrm{C}$ of $9.11 \times 10^{-4}$ for $\mathrm{MCHM}^{5}$. Additional parameters used in this calculation were the molecular weight of MCHM $(128 \mathrm{~g} / \mathrm{mol})$, the phase ratio (volume occupied by vapor/volume of liquid applied to vapor cup), and the molar volume at $37^{\circ} \mathrm{C}$ (25.4 L/mol). To determine $\mathrm{V}_{\text {vapor, }}$, we measured (with water) the total volume available within the plastic transwell insert above the level of the tissue/membrane.

\section{Equation 1:}

$\mathrm{C}_{\mathrm{vapor}(\mathrm{MCHM})}=\mathrm{C}_{\text {sample }(\mathrm{MCHM})} /(\mathrm{k}+\beta)=15.5 \mathrm{mM} /(\mathrm{k}+\beta)$ 
$\mathrm{k}=$ partition coefficient of $\mathrm{MCHM}$ at $40^{\circ} \mathrm{C}=(1 / \mathrm{HLC})=1098$

$\beta=$ phase ratio $=\mathrm{V}_{\text {vapor }} / \mathrm{V}_{\text {sample }}=\sim 700 \mu \mathrm{L} / 50 \mu \mathrm{L}=14$

$\mathrm{C}_{\text {vapor }(\mathrm{MCHM})}=(15.5 \mathrm{mmol} / \mathrm{L} \times 128 \mathrm{mg} / \mathrm{mmol}=1984 \mathrm{mg} / \mathrm{L}) /(1098+14)=1.78 \mathrm{mg} / \mathrm{L}$

$(0.00178 \mathrm{~g} / \mathrm{L} \times 25.4 \mathrm{~L} / \mathrm{mol}) / 128 \mathrm{~g} / \mathrm{mol}=0.000354=354 \mathrm{ppm}$

Some tissues were exposed to 1.55 or $15.5 \mathrm{mM}$ crude MCHM using the same method (and calculation) and an $\mathrm{HLC}$ at $40^{\circ} \mathrm{C}$ of $10.9 \times 10^{-4}$ for crude $\mathrm{MCHM}^{5}$. Because the crude MCHM consisted of $\sim 77 \% \mathrm{MCHM}\left(\mathrm{C}_{\text {sample }}(\mathrm{MCHM})=1528 \mathrm{mg} / \mathrm{L}\right)$, the estimated nominal MCHM vapor exposure concentration for crude MCHM was slightly lower ( $325 \mathrm{ppm})$. Some tissues were exposed for 1.5 hours to very high concentrations of vapors (estimated $>150,000 \mathrm{ppm}$ ) derived from $50 \mu \mathrm{L}$ of (undiluted) pure or crude $7 \mathrm{M} \mathrm{MCHM}$ as positive controls applied to the vapor cups and then cultured for an additional 22.5 hours post-exposure ( 24 hours total). Separate 6well plates were used for vehicle control and MCHM exposure groups. Following exposures, the apical surface of the ALI tissues was gently rinsed twice with $400 \mu \mathrm{L}$ PBS at 24 hours (includes exposure + post-exposure times). Basolateral culture media was also collected at 24 hours and frozen at $-80^{\circ} \mathrm{C}$ for analysis of extracellular (secreted/released) proteins via the IL-1 receptor activation assay or multiplex analysis.

\section{MTT Assay}

Cell viability (cytotoxicity) was measured at 24 hours using an MTT assay (MTT-100, MatTek). Briefly, each rinsed tissue insert was placed into $300 \mu \mathrm{L}$ of MTT reagent in a 24 -well plate and incubated for 3 hours at $37^{\circ} \mathrm{C}$. Metabolically-active cells convert the MTT to a purple dye which is proportional to viability. The tissue insert was then placed into $2 \mathrm{~mL}$ of MTT extractant in a 24-well plate and incubated overnight at room temperature. After the extraction period, $200 \mu \mathrm{L}$ of extractant was transferred to a 96-well plate (in triplicate for each tissue) and absorbance (Ab) was measured at $570 \mathrm{~nm}$. The average $A b 570 \mathrm{~nm}$ value was calculated for each tissue. Note, not all exposed tissues were tested by MTT assay because it is a "terminal" procedure and some tissues were frozen in the event that we wanted to go back later to perform RNA extraction for transcriptional analyses.

\section{IL-1 Receptor Activation Assay}

Activation of the IL-1 receptor by extracellular IL-1 proteins present in the 24-hour EpiAirway ${ }^{\mathrm{TM}}$ basolateral culture media samples was measured using an IL-1 receptor HEKBlue $^{\mathrm{TM}}$ reporter assay (InvivoGen, San Diego, CA). Briefly, $5 \times 10^{4} \mathrm{HEK}-\mathrm{Blue}$ cells were incubated in $200 \mu \mathrm{L}$ of a 1:10 culture medium:HEK-Blue test medium (cDMEM containing $100 \mu \mathrm{g} / \mathrm{mL}$ Normocin and Zeocin ${ }^{\mathrm{TM}}, 200 \mu \mathrm{g} / \mathrm{mL}$ Hygromycin B Gold, and $1 \mu \mathrm{g} / \mathrm{mL}$ Puromycin) mixture in a $96-$ well plate at $37^{\circ} \mathrm{C}$ overnight (in triplicate for each tissue). Activation of the IL-1 receptor induces secreted embryonic alkaline phosphatase (SEAP) by the HEK-Blue cells. After overnight incubation, the HEK-Blue cell-conditioned medium $(20 \mu \mathrm{L})$ was mixed with $180 \mu \mathrm{L}$ of QUANTI-blue substrate (InvivoGen). After a 20-minute incubation at $37^{\circ} \mathrm{C}$, SEAP activity was detected via measurement of $A b$ at $620 \mathrm{~nm}$. The average Ab $620 \mathrm{~nm}$ value was calculated for each tissue. 


\section{Multiplex Protein Analysis}

The Human Cytokine 42-plex Discovery Assay (Eve Technologies, Calgary, AB, Canada) was used to assay a panel of extracellular cytokines/chemokines and growth factors in the 24-hour EpiAirway $^{\mathrm{TM}}$ basolateral culture media samples (in duplicate for each tissue). The 42 analytes measured were epidermal growth factor, eotaxin-1, fibroblast growth factor-2, FMS-like tyrosine kinase-3 ligand, fractalkine, granulocyte colony-stimulating factor (G-CSF), granulocyte macrophage colony-stimulating factor (GM-CSF), growth-regulated alpha protein, interferonalpha 2, interferon-gamma, interferon-gamma-inducible protein 10 (IP-10), monocyte chemoattractant protein-1, monocyte chemoattractant protein-3, macrophage-derived chemokine, macrophage inflammatory protein-1-alpha, macrophage inflammatory protein-1-beta, plateletderived growth factor-AA, platelet-derived growth factor-AB/BB, regulated on activation normal T cell expressed and secreted protein (RANTES), soluble CD40 ligand, transforming growth factor-alpha (TGFa), tumor necrosis factor-alpha, tumor necrosis factor-beta, vascular endothelial growth factor-A, IL-1-alpha (IL-1a), IL-1-beta, IL-1 receptor antagonist (IL-1Ra), IL-2, IL-3, IL4, IL-5, IL-6, IL-7, IL-8, IL-9, IL-10, IL-12 (p40), IL-12 (p70), IL-13, IL-15, IL-17A, and IL-18. Data were reported in $\mathrm{pg} / \mathrm{mL}$ and the average $\mathrm{pg} / \mathrm{mL}$ value was calculated (for each analyte) for each tissue.

\section{Statistics}

One-way ANOVA (with Tukey's test) was performed using GraphPad Prism 6 software (LaJolla, CA). All data are presented as mean \pm SEM with a two-sided p-value $<0.05$ considered statistically significant. 


\section{Results}

\section{Cell Viability}

An MTT assay was used to determine if acute exposure of human airway epithelial tissues to

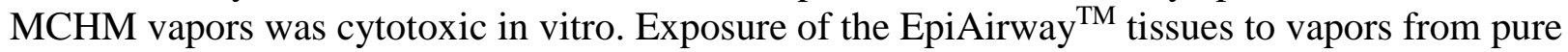
or crude MCHM at 35 or 350 ppm for 6 hours induced no significant changes in cell viability (compared to vehicle control) at 24 hours (Figure 1). There were also no noticeable changes in the apical morphology of these vapor-exposed tissues (including cell layer integrity, cilia movement, and mucus production), which was determined by visual inspection of the surface of the tissue by light microscopy (data not shown). However, there was a potent cytotoxic response induced by acute exposure for 1.5 hours to very high vapor concentrations derived from pure or crude $7 \mathrm{M}$ MCHM as positive controls (Figure 1).

\section{IL-1 Receptor Activation}

IL-1 receptor activation was measured to determine if acute exposure of human airway epithelial tissues to MCHM vapors induced a pro-inflammatory response in vitro via the production of IL1 proteins, which include agonistic (IL-1a and IL-1b) and antagonistic (IL-1Ra) ligands of the IL-1 receptor. Culture media collected at 24 hours from EpiAirway ${ }^{\mathrm{TM}}$ tissues exposed to vapors from pure or crude MCHM at 35 or 350 ppm for 6 hours induced no significant increase in IL-1 receptor activation (compared to vehicle control). However, IL-1 receptor activation was significantly increased $\sim 2$-fold by acute exposure for 1.5 hours to vapors derived from pure or crude $7 \mathrm{M}$ MCHM as positive controls (Figure 2).

\section{Cytokine and Chemokine Profile}

An array of growth factors, cytokines, and chemokines were measured via multiplex assay to determine if acute exposure of human airway epithelial tissues to MCHM vapors induced a specific pro-inflammatory signature in vitro. Culture media collected at 24 hours from EpiAirway $^{\mathrm{TM}}$ tissues exposed to vapors from pure or crude MCHM at 35 or $350 \mathrm{ppm}$ for 6 hours induced no significant changes in any of the 42 analytes measured (compared to vehicle control). However, IL-1a and IL-1Ra were significantly increased ( 14- to 15-fold for IL-1a and 10- to 11 -fold for IL-1Ra over vehicle controls) by acute exposure for 1.5 hours to vapors derived from pure or crude $7 \mathrm{M}$ MCHM as positive controls (Figure 3A) which mirrored IL-1 receptor activation (Figure 2). TGFa and RANTES (Figure 3A) as well as GM-CSF, IL-15, IP-10, and IL6 (Figure 3B) protein levels in 24-hour culture media were also significantly increased, and only G-CSF significantly decreased (Figure 3C), by exposure for 1.5 hours to vapors derived from pure or crude $7 \mathrm{M}$ MCHM. We did not assay these proteins in the apical rinse, but we have done so in previous studies using ALI tissues with diacetyl and observed increased IL-1a, IL-1Ra, and IL-8 in the apical rinse; however, in addition to these cytokines, other analytes were found to be increased in the basolateral culture media ${ }^{12}$.

The data used to produce these figures are accessible online at https://doi.org/10.22427/NTPDATA-RR-7. 
Preliminary Evaluation of 4-Methylcyclohexylmethanol in an In Vitro Human Airway Model

\section{Discussion}

The strong licorice-smelling odor observed in the aftermath of the spill of crude MCHM into the Elk River in 2014 indicated that inhalation of MCHM vapors was a potential route of chemical exposure. There were also reports of respiratory illness/cough ${ }^{4}$ suggestive of chemical-induced adverse airway effects. Thus, in a preliminary evaluation we utilized an organotypic human ALI culture model (EpiAirway ${ }^{\mathrm{TM}}$ ) derived from TBE cells of a single donor to determine if there was any potential for MCHM-induced airway toxicity in vitro following acute exposure to MCHM vapors for 6 hours, which might warrant future inhalation toxicity testing in vivo. Based on limited human exposure and in vivo data, it is unknown if upper airway (TBE) cells are the primary target of inhaled MCHM vapors.

Results using the EpiAirway ${ }^{\mathrm{TM}}$ ALI model showed that there were no adverse airway effects in vitro following a 6-hour exposure to MCHM vapors at concentrations of 35 or $350 \mathrm{ppm}$, both in terms of cytotoxicity or induction of a pro-inflammatory response (via measurements of IL-1 receptor activation and multiple cytokines/chemokines in a multiplex assay). The MCHM exposure concentrations tested were $\sim 90$ - to 900 -fold greater than human exposure levels as predicted while showering ${ }^{5}$. Also, the exposure duration was much longer (6 hours vs.

10 minutes). Based on these preliminary data using the EpiAirway ${ }^{\mathrm{TM}}$ ALI model derived from a single donor, acute exposure of human airway epithelial tissues to MCHM vapors for 6 hours was not toxic in vitro at concentrations relevant to human inhalation exposure $(<0.50 \mathrm{ppm})$. Quantitative structure-activity relationship (QSAR) analysis based on MetaDrug pulmonary toxicity indicated "insufficient structural similarity"; however, analysis based on the ADMET predictor of respiratory sensitization was "negative" for $\mathrm{MCHM}^{13}$, which lends further support to these in vitro findings.

For this study, we were limited by the solubility of MCHM (in water) in the selection of the maximum MCHM vapor exposure concentration tested. The aqueous concentration of $15.5 \mathrm{mM}$ $\mathrm{MCHM}$ is close to the maximum solubility of pure MCHM in water $(2,250 \mathrm{mg} / \mathrm{L}$ or $17.6 \mathrm{mM})$, thus 350-400 ppm was the highest (estimated) nominal vapor exposure concentration achievable using pure MCHM diluted in water. Also, the estimation of the nominal vapor concentration of $350 \mathrm{ppm}$ (within the headspace) derived from $15.5 \mathrm{mM}$ MCHM added to the vapor cups was theoretical based on a calculation we have previously used for diacetyl ${ }^{10}$ and assumed a closed system (air-tight silicone seal between the vapor cup and plastic insert). Furthermore, the HLC for pure and crude MCHM used in this calculation was only reported by Sain et al.$^{5}$ at $40^{\circ} \mathrm{C}$, not $37^{\circ} \mathrm{C}$. We are currently evaluating in vitro volatile exposure systems with in-line monitoring and better control over vapor dosimetry.

Another study limitation was the use of a single donor (TBE-20), which does not account for human variability and therefore limits the extrapolation of our findings to the general human population. One could argue that the airway epithelial cells from this specific donor might be "unresponsive" to chemical exposure; however, we have previously used this in vitro human ALI model derived from the same donor to characterize airway effects induced by exposure to diacetyl vapors ${ }^{7-9}$. Others have also reported responsiveness of these donor airway cells in ALI cultures to chemical vapor exposure ${ }^{14}$. Furthermore, we previously observed consistent responses of EpiAirway ${ }^{\mathrm{TM}}$ tissues based on proteomic/secretomic analyses across multiple donors including TBE-20 following diacetyl exposure ${ }^{7 ; 8}$. 
In contrast to the airway/lung microenvironment, there were no resident or recruitedinflammatory leukocytes in this ALI model. But, we have previously shown the induction of a pro-inflammatory response, measured via multiplex assay, by diacetyl vapors despite the absence of these cell types ${ }^{9}$. Thus, these airway epithelial tissues (ALI cultures) have the capacity to produce a robust pro-inflammatory response following exposure to a respiratory toxicant. Follow-up studies should address these limitations via the testing of different donors (to better reflect variation within the human population) and alternative airway models with additional cell types including leukocytes ${ }^{15 ; 16}$ to compare to our findings using the EpiAirway ${ }^{\mathrm{TM}}$ model. The pro-inflammatory response induced by exposure of EpiAirway ${ }^{\mathrm{TM}}$ tissues to very high MCHM vapor concentrations (derived from pure or crude $7 \mathrm{M} \mathrm{MCHM}$ as positive controls) was perhaps due to the potent cytotoxicity and hence passive release of cytokines/chemokines by necrotic cells. However, there were a number of cytokines/chemokines that were unaffected by this high level of vapor exposure, so this was likely not entirely the case.

This study was intended as a preliminary evaluation of acute airway effects (cytotoxicity, IL-1 receptor activation, and production of multiple cytokines/chemokines) in vitro, specifically for EpiAirway $^{\mathrm{TM}}$ ALI tissues derived from a single donor exposed to MCHM vapors for 6 hours. Future studies should address different exposure regimens and additional endpoints of pulmonary toxicity (e.g., reactive oxygen species (ROS) production as a measure of oxidative stress). Regarding the exposure regimen used in this study, the objective was specifically to assess airway effects following a single acute exposure to the highest (estimated) achievable MCHM vapor concentration ( $350 \mathrm{ppm})$ based on the maximum solubility of MCHM in water. However, multiple exposures to MCHM vapors over time (e.g., on alternating days) with recovery in future studies would better reflect a scenario of repeated exposure to crude MCHM vapors likely experienced by individuals following the Elk River spill. 


\section{References}

1. Foreman WT, Rose DL, Chambers DB, Crain AS, Murtagh LK, Thakellapalli H, Wang KK. Determination of (4-methylcyclohexyl)methanol isomers by heated purge-and-trap GC/MS in water samples from the 2014 Elk River, West Virginia, chemical spill. Chemosphere. 2015; 131:217-224. http://dx.doi.org/10.1016/j.chemosphere.2014.11.006

2. Three Kanawha schools close early for water quality issues. Charleston, WV: Charleston Daily Mail; 2014. http://www.wvea.org/content/three-kanawha-schools-closed-thursday-waterquality-issues.

3. West Virginia Bureau for Public Health (WVBPH), Agency for Toxic Substances Disease Registry (ATSDR). 2014. Elk River chemical spill health effects: Findings of emergency department record review. https://dhhr.wv.gov/News/chemicalspill/Documents/ElkRiverMedicalRecordSummary.pdf.

4. Thomasson ED, Scharman E, Fechter-Leggett E, Bixler D, Ibrahim S, Duncan MA, Hsu J, Scott M, Wilson S, Haddy L et al. Acute health effects after the Elk River chemical spill, West Virginia, January 2014. Public Health Rep. 2017; 132(2):196-202.

https://doi.org/10.1177/0033354917691257

5. Sain AE, Dietrich AM, Smiley E, Gallagher DL. Assessing human exposure and odor detection during showering with crude 4-(methylcyclohexyl) methanol (MCHM) contaminated drinking water. Sci Total Environ. 2015; 538:298-305.

http://dx.doi.org/10.1016/j.scitotenv.2015.08.050

6. National Toxicology Program (NTP). 2014. West Virginia chemical spill: NTP research project plan. https://ntp.niehs.nih.gov/ntp/research/areas/wvspill/project_508.pdf.

7. Brass DM, Gwinn WM, Valente AM, Kelly FL, Brinkley CD, Nagler AE, Moseley MA, Morgan DL, Palmer SM, Foster MW. The diacetyl-exposed human airway epithelial secretome: New insights into flavoring-induced airways disease. Am J Respir Cell Mol Biol. 2017; 56(6):784-795. http://dx.doi.org/10.1165/rcmb.2016-0372OC

8. Foster MW, Gwinn WM, Kelly FL, Brass DM, Valente AM, Moseley MA, Thompson JW, Morgan DL, Palmer SM. Proteomic analysis of primary human airway epithelial cells exposed to the respiratory toxicant diacetyl. J Proteome Res. 2017; 16(2):538-549.

http://dx.doi.org/10.1021/acs.jproteome.6b00672

9. Gwinn WM, Flake GP, Bousquet RW, Taylor GJ, Morgan DL. Airway injury in an in vitro human epithelium-fibroblast model of diacetyl vapor exposure: diacetyl-induced basal/suprabasal spongiosis. Inhalation Toxicol. 2017; 29(7):310-321. http://dx.doi.org/10.1080/08958378.2017.1369604

10. Kelly FL, Sun J, Fischer BM, Voynow JA, Kummarapurugu AB, Zhang HL, Nugent JL, Beasley RF, Martinu T, Gwinn WM et al. Diacetyl induces amphiregulin shedding in pulmonary epithelial cells and in experimental bronchiolitis obliterans. Am J Respir Cell Mol Biol. 2014; 51(4):568-574. http://dx.doi.org/10.1165/rcmb.2013-0339OC 
11. Jackson Jr GR, Bolmarcich J, Oldach J, Klausner M, Hayden PJ. In vitro evaluation of airway toxicity using the EpiAirway organotypic in vitro human airway model. Poster presented at: Society of Toxicology 2011. Washington, DC. 2011.

12. Gwinn WM, Flake G, Bousquet RW, Morgan DL. Airway epithelial injury, fibroblast changes, and cytokine/chemokine profiles induced by exposure of human EpiAirway-FT tissues to diacetyl vapors. The Toxicologist: Supplement to Toxicol Sci. 2015; 144(1):Abstract \#242.

13. Auerbach SS, Choksi N, Ferguson S, Hsieh J-H, Svoboda D, Myatt G, Wampole M, Sedykh A, Prous Jr J, Masten S et al. HTS and SAR analysis of chemicals from the Elk River spill. The Toxicologist: Supplement to Toxicol Sci. 2015; 144(1):Abstract \#2223.

14. Seagrave J, Herrera L, Weber W, Grotendorst G. Sulfur mustard-induced responses of airway and skin in vitro. Poster presented at: Society of Toxicology 2011. Washington, DC. 2011.

15. Rothen-Rutishauser BM, Kiama SG, Gehr P. A three-dimensional cellular model of the human respiratory tract to study the interaction with particles. Am J Respir Cell Mol Biol. 2005; 32(4):281-289. http://dx.doi.org/10.1165/rcmb.2004-01870C

16. Rothen-Rutishauser B, Blank F, Muhlfeld C, Gehr P. In vitro models of the human epithelial airway barrier to study the toxic potential of particulate matter. Expert Opin Drug Metab Toxicol. 2008; 4(8):1075-1089. http://dx.doi.org/10.1517/17425255.4.8.1075 


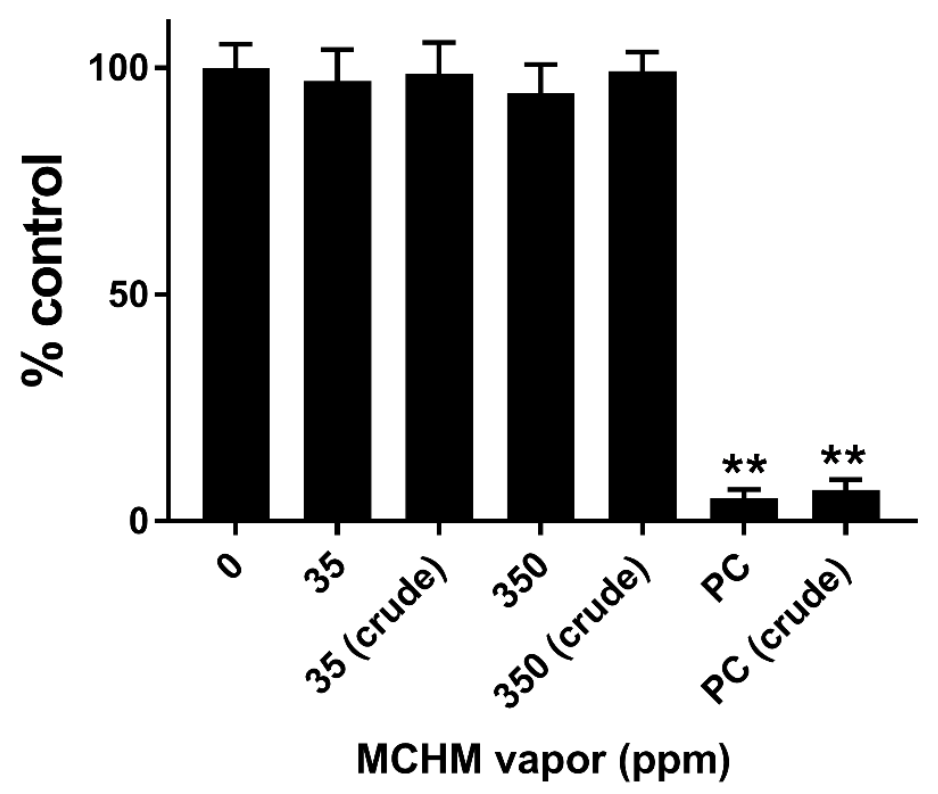

Figure 1. Cell Viability

EpiAirway ${ }^{\mathrm{TM}}$ tissues from a single donor were exposed to vehicle or MCHM vapors as described in Materials and Methods. Cell viability (cytotoxicity) was measured at 24 hours after acute exposure using an MTT assay (Ab $570 \mathrm{~nm}$ ). MTT extractant was assayed in triplicate and the $\mathrm{Ab} 570 \mathrm{~nm}$ values averaged for each tissue. Data are presented as mean \pm SEM for $\%$ control (combined data from two separate experiments are shown with combined " $n$ " (for total tissues) $=8,6,6-8$, and 3-5 for the 0 (vehicle control), 35, 350, and positive control (PC) exposure groups, respectively); $* *=p<0.001$ vs. vehicle control (using one-way ANOVA with Tukey's test). 


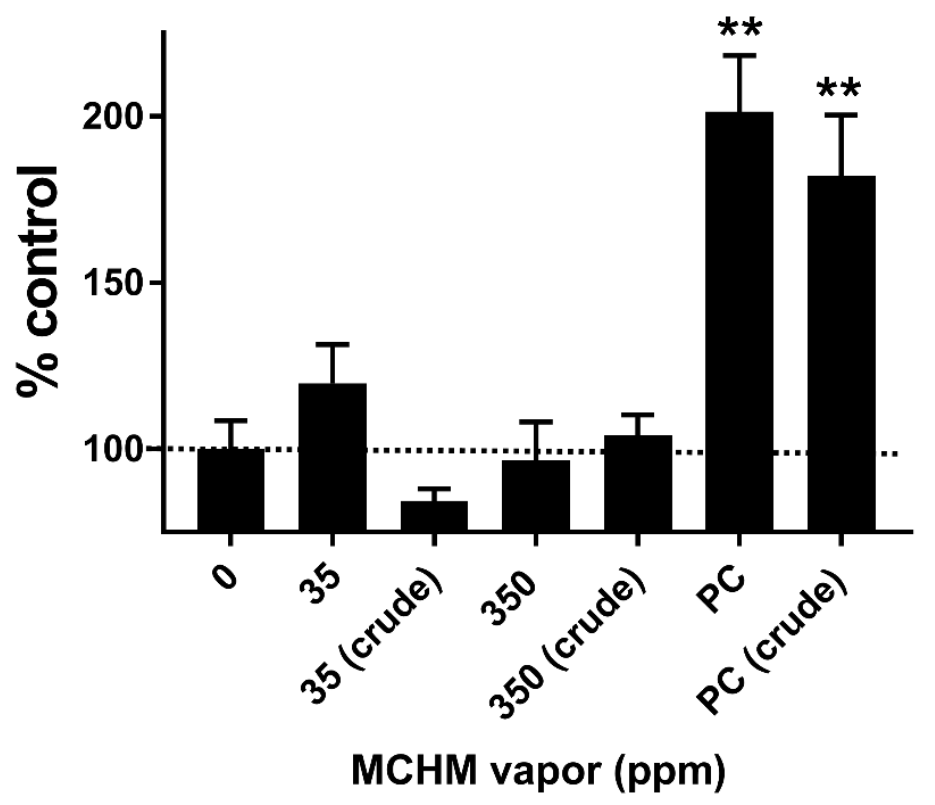

Figure 2. IL-1 Receptor Activation

EpiAirway ${ }^{\mathrm{TM}}$ tissues from a single donor were exposed to vehicle or MCHM vapors as described in Materials and Methods. Culture media were collected at 24 hours after acute exposure. Activation of the IL-1 receptor by IL-1 proteins present in the culture media were measured using an IL-1 receptor HEK-Blue ${ }^{\mathrm{TM}}$ reporter assay (Ab $\left.620 \mathrm{~nm}\right)$. Culture media was assayed in triplicate and the Ab $620 \mathrm{~nm}$ values averaged for each tissue. Data are presented as mean \pm SEM for $\%$ control (combined data from two separate experiments are shown with combined " $\mathrm{n}$ " (for total tissues) $=10,8,10$, and 6-8 for the 0 (vehicle control), 35,350 , and positive control (PC) exposure groups, respectively); $* *=p<0.001$ vs. vehicle control (using one-way ANOVA with Tukey's test). The dotted horizontal line on the graph indicates $100 \%$. Note, IL-1 receptor activation for 35 ppm crude MCHM was decreased vs. 0, but the difference was not statistically significant. 

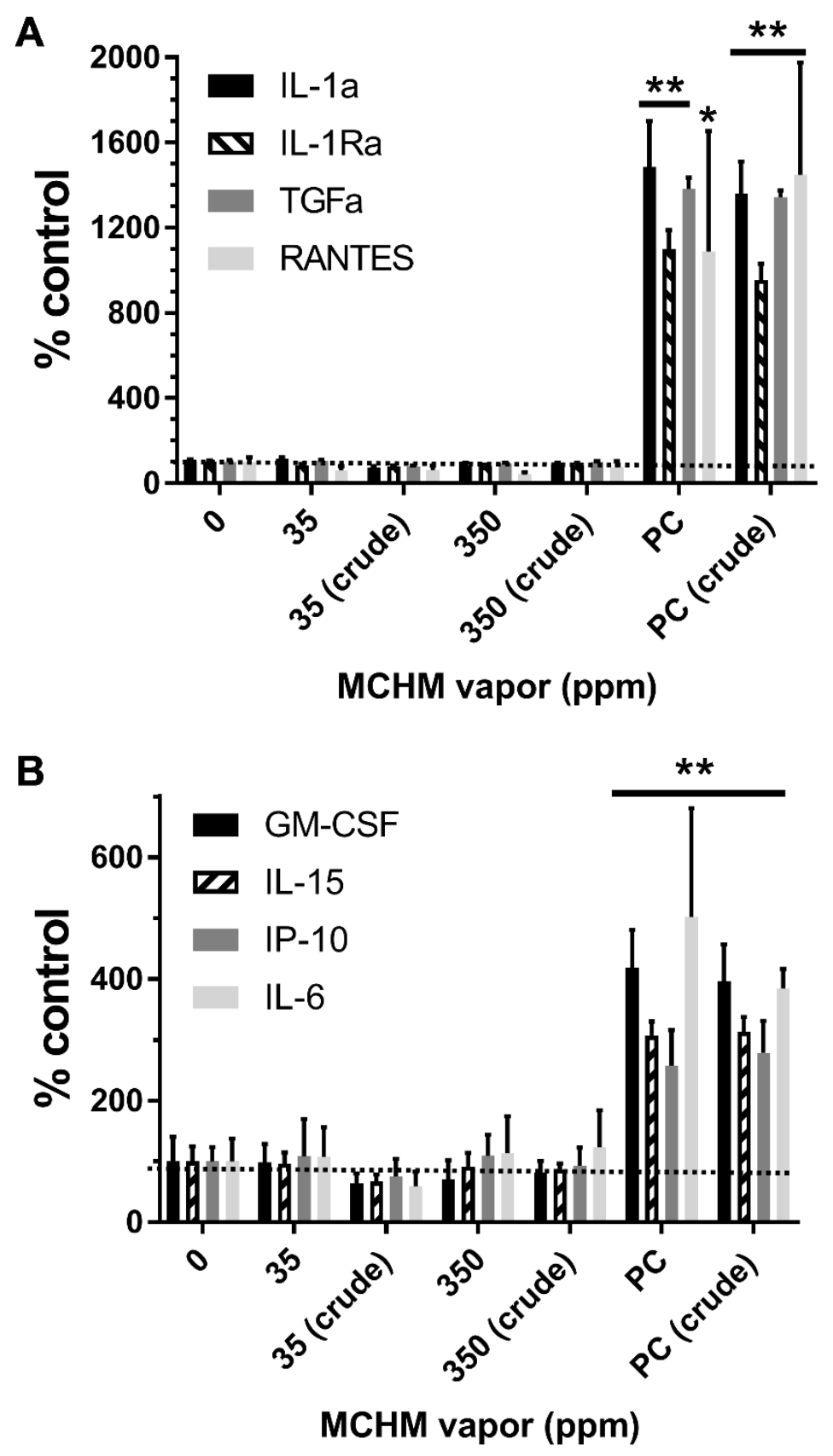


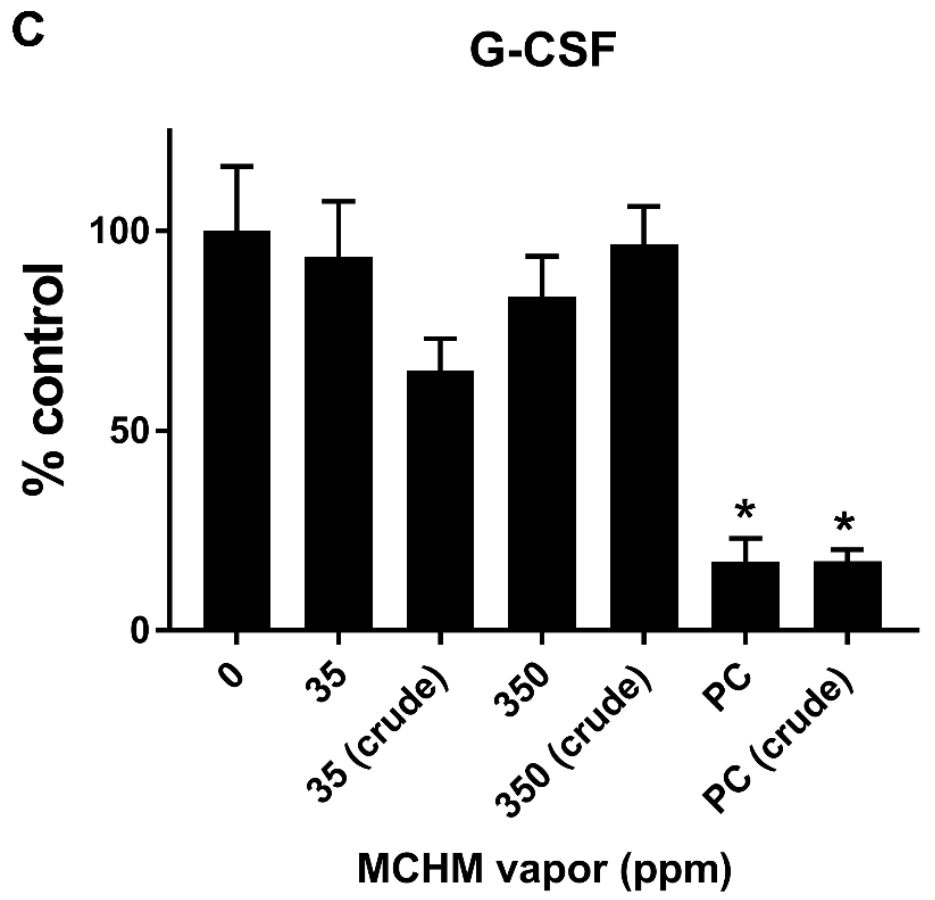

\section{Figure 3. Cytokine and Chemokine Production}

EpiAirway ${ }^{\mathrm{TM}}$ tissues from a single donor were exposed to vehicle or MCHM vapors as described in Materials and Methods. Cytokines and chemokines were measured via multiplex protein analysis in culture media collected 24 hours after acute exposure. Culture media was assayed in duplicate and the $\mathrm{pg} / \mathrm{mL}$ values averaged (for each analyte) for each tissue. A. IL-1a, IL$1 \mathrm{Ra}, \mathrm{TGFa}$, and RANTES ( $* *=\mathrm{p}<0.001$ for each analyte vs. its respective vehicle control using one-way ANOVA with Tukey's test, except the PC group $(*=\mathrm{p}<0.01)$ for RANTES). B. GM-CSF, IL-15, IP-10, and IL-6 ( $* *=p<0.001$ for each analyte vs. its respective vehicle control using one-way ANOVA with Tukey's test). C. G-CSF $(*=\mathrm{p}<0.01$ vs. vehicle control using one-way ANOVA with Tukey's test). Data are presented as mean \pm SEM for $\%$ control (combined data from two separate experiments are shown with combined " $n$ " (for total tissues) $=7,6,7$, and 3 for the 0 (vehicle control), 35, 350, and positive control (PC) exposure groups, respectively). The dotted horizontal lines on the graphs in A and B indicate 100\%. Note (for graph in C), G-CSF for 35 ppm crude MCHM was decreased vs. 0, but the difference was not statistically significant. 


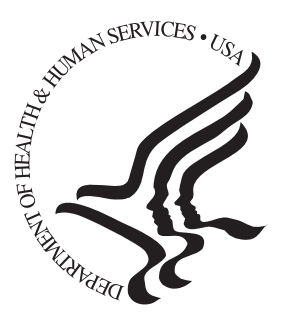

\section{National Toxicology Program}

NTP Central Data Managment, MD K2-05

National Insitute of Enviromental Health Sciences

P.O. Box 12233

Research Triangle Park, NC 27709

http://ntp.niehs.nih.gov 